Article

\title{
The Potential Cost-Effectiveness of Pre-Exposure Prophylaxis Combined with HIV Vaccines in the United States
}

\author{
Blythe J. S. Adamson 1,*, Josh J. Carlson ${ }^{1}$, James G. Kublin ${ }^{2,3}$ and Louis P. Garrison, Jr. ${ }^{1,3}$ \\ 1 Pharmaceutical Outcomes Research and Policy, Department of Pharmacy, University of Washington, \\ Seattle, WA 98115, USA; carlsojj@uw.edu (J.J.C.); lgarrisn@uw.edu (L.P.G.J.) \\ 2 HIV Vaccine Trials Network, Fred Hutchinson Cancer Research Center, Seattle, WA 98109, USA; \\ jkublin@fredhutch.org \\ 3 Department of Global Health, University of Washington, Seattle, WA 98115, USA \\ * Correspondence: blythem@uw.edu; Tel.: +1-253-225-4466
}

Academic Editor: Alfredo Torres

Received: 24 March 2017; Accepted: 19 May 2017; Published: 24 May 2017

\begin{abstract}
This economic evaluation aims to support policy-making on the combined use of pre-exposure prophylaxis (PrEP) with HIV vaccines in development by evaluating the potential cost-effectiveness of implementation that would support the design of clinical trials for the assessment of combined product safety and efficacy. The target study population is a cohort of men who have sex with men (MSM) in the United States. Policy strategies considered include standard HIV prevention, daily oral PrEP, HIV vaccine, and their combination. We constructed a Markov model based on clinical trial data and the published literature. We used a payer perspective, monthly cycle length, a lifetime horizon, and a 3\% discount rate. We assumed a price of $\$ 500$ per HIV vaccine series in the base case. HIV vaccines dominated standard care and PrEP. At current prices, PrEP was not cost-effective alone or in combination. A combination strategy had the greatest health benefit but was not cost-effective (ICER $=\$ 463,448 /$ QALY) as compared to vaccination alone. Sensitivity analyses suggest a combination may be valuable for higher-risk men with good adherence. Vaccine durability and PrEP drug prices were key drivers of cost-effectiveness. The results suggest that boosting potential may be key to HIV vaccine value.
\end{abstract}

Keywords: economic evaluation; mathematical modeling; HIV vaccines; pre-exposure prophylaxis; cost-effectiveness

\section{Introduction}

HIV treatment and prevention in the United States (USA) requires substantial societal resources and the treatment of HIV-infected patients is generally cost-effective. Based on economic models, if treated, a person infected with HIV at age 35 in the U.S. will, on average, suffer from lower quality and length of life and accumulate $\$ 247,500$ (2015 USD) more in lifetime medical costs compared to people who are not HIV infected [1-3]. Federal funds in 2016 allocated $\$ 20$ billion for domestic HIV care and \$1 billion for domestic HIV prevention [4]. To date, only one drug has a Food and Drug Administration (FDA)-approved indication for prevention. Truvada ${ }^{\circledR}$ is a single-pill fixed-dose antiretroviral combination of tenofovir disoproxil fumarate (TDF) and emtricitabine (FTC) launched in 2004 to treat HIV (Gilead Sciences, Inc., Foster City, CA, USA). The FDA approval expanded Truvada's ${ }^{\circledR}$ indication in 2012 as a safe and effective daily oral medication to reduce the risk of sexually acquired HIV infection, a form of pre-exposure prophylaxis (PrEP). PrEP studies including Pre-exposure Prophylaxis Initiative (iPrEX), Pre-exposure prophylaxis to prevent the acquisition of HIV-1 infection (PROUD), France Recherche Nord et Sud Sida- HIV et Hépatites (ANRS), Intervention Préventive de l'Exposition aux Risques avec et pour les Gays (IPERGAY), and Kaiser Permanente studies 
reported efficacy ranging from $42 \%$ to $99 \%$ with adherence strongly correlated with effectiveness [5-9]. Side effects in some patients include diarrhea, nausea, liver toxicity, and bone mineral density loss. By 2015, Truvada ${ }^{\circledR}$ had the largest market share (17\%) of all HIV drugs with no competing HIV drugs on the market for prophylaxis. The potential market for PrEP is estimated as 1.2 million people, including $25 \%$ of the estimated 4.5 million men who have sex with men (MSM) in the U.S. [10-12]. The average wholesale price of Truvada ${ }^{\circledR}$ was $\$ 1646$ for a 30-day supply in 2015 whether used for prevention or treatment of HIV [13].

HIV vaccines in development, and currently in clinical trials, may eventually be used in place of or in combination with PrEP. A Phase III study in Thailand with more than 16,000 participants (labeled as RV144 and referred to as "the Thai trial" in this paper) established an HIV vaccine candidate with an average $31 \%$ preventive efficacy over three years [14]. Immunogenicity results from a follow-up study of RV144 participants re-vaccinated years later suggests boosting may be effective [15]. A National Institute of Allergy and Infectious Diseases (NIAID)-funded confirmatory trial (HVTN 702) in South Africa was launched in 2017 to evaluate the safety and preventive efficacy of ALVAC-HIV (vCP2438) vaccine prime with bivalent subtype C gp120/MF59 boosts (see descriptions in Table A1) [16,17]. Compared to the Thai trial, the HVTN 702 vaccine regimen, which matches the HIV sub-type circulating in Southern Africa, replaces alum with the potentially more potent adjuvant MF59 and adds a fifth dose at 12 months to the regimen schedule [17]. This pivotal HIV vaccine trial hypothesizes an average vaccine efficacy (VE) of 50\% over 24 months, and is scheduled to be completed in 2021.

Previous economic evaluations have separately examined the cost-effectiveness of PrEP or HIV vaccines in the USA but none have modeled the potential outcomes when combining these products [18-23], as shown in a recent review of HIV vaccine cost-effectiveness studies [24]. For the treatment of HIV, Truvada ${ }^{\circledR}$ is highly cost-effective when used in combination with other drugs, but the cost-effectiveness estimates for prevention are mixed in reviews [21,25,26]. If an HIV vaccine is launched in the USA, experts may consider modifying PrEP clinical guidelines to inform the most efficient use in combination with HIV vaccines [27]. This analysis is the first to assess the potential cost-effectiveness of combining PrEP with an HIV vaccine in comparison to either alone for MSM in the U.S. Specifically, the objective of our study is to identify the potential cost-effectiveness of HIV vaccines co-administered with PrEP and to investigate thresholds for vaccine characteristics for efficient use in MSM. The findings have implications not only for potential uptake but also for the prioritization of PrEP and vaccine candidates progressing through the clinical development pipeline.

\section{Materials and Methods}

This modeling study followed methodology recommendations from the Second Panel on Cost-Effectiveness in Health and Medicine and meets standardized reporting requirements from the Consolidated Health Economics Evaluation Reporting Standards (CHEERS) statement [28,29].

\subsection{Study Population}

The analysis evaluated policy strategies for potential implementation of HIV prevention interventions in a cohort of HIV-negative MSM in the USA The base-case analysis models men of average age 30 years until death, i.e., a lifetime horizon. A sub-group analysis focuses on a cohort of "high-risk" men, defined as having anal sex without a condom in the last 12 months, based on clinical practice guidelines recommending PrEP [27].

\subsection{Model Overview}

We developed a Markov health-state transition model of HIV infection and disease progression and used the model to estimate clinical benefits, total costs, and the cost-effectiveness of strategies delivering HIV vaccines and PrEP alone or in combination. We developed a model based on previous works by Sanders et al. and Bayoumi et al. [30,31]. Importantly, we add functions to describe PrEP of varying duration and HIV vaccines with waning efficacy and boosting. Health states, seen in Figure 1, 
are connected by difference equations solved at monthly time steps. Parameter values were informed by the most recent peer-reviewed literature. The HIV prevention strategies evaluated include: PrEP alone, HIV vaccines alone, co-administration of PrEP and HIV vaccines, and a reference base-case of standard HIV prevention without PrEP or vaccines. An Impact Inventory (Table A2) catalogues the intervention costs and effects within and outside the healthcare sector and identifies components included in this analysis [28].
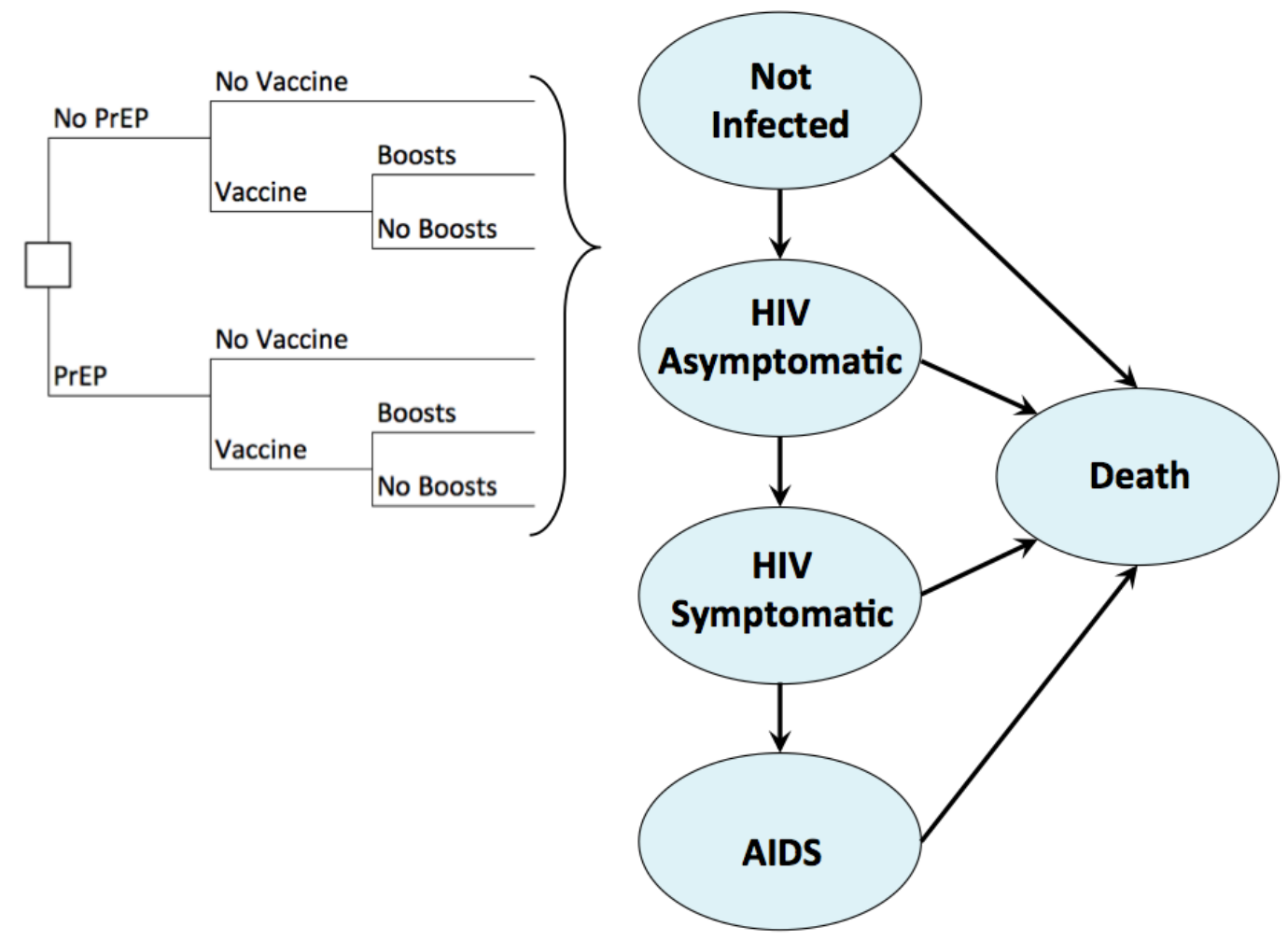

Figure 1. Simplified conceptual diagram of health states in the Markov model.

\subsection{Model Inputs}

Table 1 summarizes the key model inputs.

\subsubsection{HIV Incidence}

HIV-negative men entering the model had an age-dependent risk of infection. The input values for HIV incidence were calculated from Centers for Disease Control (CDC) surveillance data on newly detected cases and population sizes from the U.S. Census Bureau (Table 1) [32,33]. Cross-sectional MSM incidence was extrapolated to future years. Given the uncertainty in HIV-incidence among PrEP-indicated MSM, we scaled the observed trend by age to match the incidence levels observed in the PROUD study participants to represent the high-risk sub-group, also with HIV incidence dependent on age (Figure A1) [8]. For example, at the age of greatest average risk, 30-34 years, the HIV incidence input value for general MSM was 1.2 infections per 100 person-years and for high-risk MSM was 10.5 infections per 100 person-years. Incidence rates were converted into the probability of infection in a monthly time step.

\subsubsection{Clinical Inputs}

Newly infected HIV patients progressed over time through health states defined by CD4+ T-cell count categories $(>500,200-499$, and $<200$ T-cells per $\mathrm{mL}$ ). The probability of monthly transitions through progressing health states represent population averages based on the published literature 
(Table 1). Age-and gender-specific baseline mortality rates were calculated from 2010 United States Life Tables [34]. Based on the Strategies for Management of Antiretroviral Therapy (SMART) Study and Evaluation of Subcutaneous Proleukin in a Randomized International Trial (ESPRIT) in well-controlled HIV infected individuals, patients with CD4 counts ranging from 200-500 had a 1.77 times increased hazard of non-AIDS death (95\% CI: 1.17-2.55)compared to the general population, but those with CD4 $>500$ had no increased risk of death [35]. Patients with CD4 <200 could die from AIDS in addition to their baseline risk of death from other causes [36].

\subsubsection{Health State Utility}

We identified preference-based utility weights (Table 1) for HIV health states defined by CD4 T-cell count categories (Figure 1) in the published literature [30,37-40]. Utilities for uninfected men are stratified by age and based on healthy males in the general U.S. population [37]. To account for the range of adverse events associated with PrEP, such as bone mineral density loss, the time using PrEP had a utility decrement of 0.008 applied to each quarter of use (ranging $0-0.1$ in the sensitivity analyses). To adjust for potential HIV vaccine reactogenicity, men lost the equivalent of one quality-adjusted day at the time of each vaccine injection.

\subsubsection{Intervention Effectiveness}

We define the standard of care as routine HIV testing, risk reduction counseling, and no availability of PrEP or HIV vaccines. The base-case PrEP strategy assumes average adherence corresponding to $86 \%$ effectiveness in reduction in HIV incidence, based on the Partners in Prevention and IPERGAY studies, and an average duration of 5 years $[8,41,42]$. Scenarios with lower adherence to PrEP drugs had 53\% efficacy, based on iPrEX study findings [6,43], and scenarios with higher PrEP adherence had 99.9\% effectiveness based on an observational study of PrEP users in the Kaiser Permanente Health System [9]. Ranges of PrEP duration (0-10 years) and effectiveness (40-99.9\%) are explored in the sensitivity analysis. Base-case HIV vaccination resembled the HVTN 702 regimen with a five-dose series administered over 12 months (Figure A2). We modified the proportional hazards model by Hankins et al., originally fitted to the 31\% vaccine efficacy (VE) observed in the Thai trial [44], to describe the expected waning over time with an average of 50\% VE at 24 months as expected in HVTN 702. The time-dependent reduction in the likelihood of HIV acquisition following a complete HIV vaccine series followed the equation

$$
V E_{t}=1-\exp (-2.88+0.76 \times(\log ((t+0.001) \times 30))
$$

where $t$ is the time in months since the first dose of the most recent vaccination series (see Figure 2 and Appendix Figure A2). We assumed that re-vaccination five years later boosted immunity to the initial levels followed by the same rate of exponential decay in protection from infection [45]. The PrEP-Vaccine combination strategy assumes the cohort of MSM initiates PrEP at the time of vaccination, and then they continue PrEP for five years and receive HIV vaccine boosts every 5 years (varying 0-10 years in sensitivity analyses). Figure 2 shows the average efficacy for each strategy over time. We assume that the combined effectiveness is multiplicative,

$$
p_{t}=\left(1-R R_{P r E P}\right) \times\left(1-V E_{t}\right)
$$

where $p_{t}$ is the reduction in likelihood of HIV infection from the combination at month $t$. 


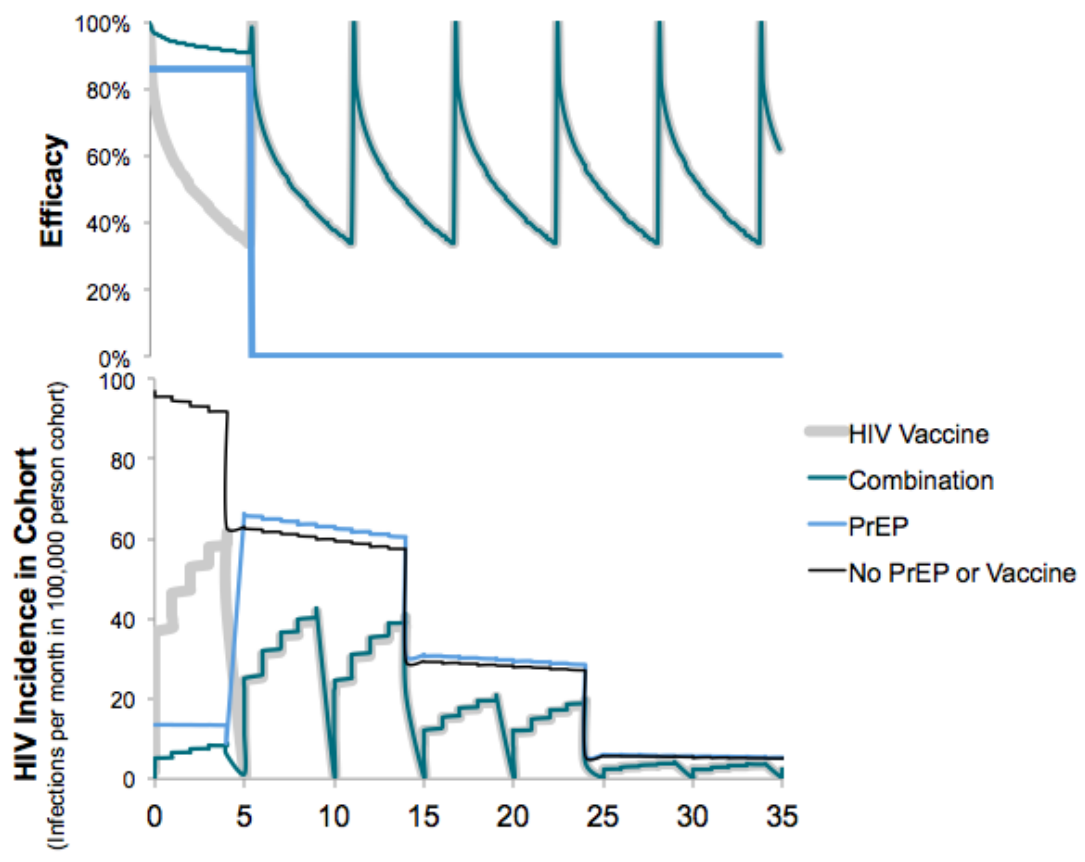

Years From Initiation

Figure 2. Efficacy and epidemic impact of HIV prevention strategies. The top panel shows the average efficacy over time given each strategy and the lower panel shows the number of new infections per month per 100,000 persons in the cohort of men. Baseline HIV incidence declines with age categories.

\subsubsection{Costs}

HIV-related healthcare costs were projected from a US health care payer perspective over the patient lifetime horizon. Inputs were derived from the published literature and adjusted to 2015 US dollars using the medical consumer price index [46,47]. A cost study of USA healthcare expenditures among HIV patients, stratified by CD4-count categories, provided the distribution and types of healthcare expenditures for HIV patients [48].

Table 1. Key model inputs.

\begin{tabular}{ccccc}
\hline Parameter & \multirow{2}{*}{ Value } & \multicolumn{2}{c}{ Sensitivity Ranges } & \multirow{2}{*}{ Reference } \\
\cline { 3 - 4 } & & Lower & Upper & \\
\hline HIV Incidence (Per 100 Person-Years) & & & \\
\hline 25-34 year old MSM in United States & $0.66 \%$ & $0.56 \%$ & $0.76 \%$ & {$[32,33]$} \\
35-44 year old MSM in United States & $0.46 \%$ & $0.38 \%$ & $0.55 \%$ & {$[32,33]$} \\
45-54 year old MSM in United States & $0.24 \%$ & $0.19 \%$ & $0.29 \%$ & {$[32,33]$} \\
High-risk scenario & $2.0 \%$ & $1.0 \%$ & $4.0 \%$ & {$[50]$} \\
\hline Intervention Efficacy & \multicolumn{3}{c}{} \\
\hline Vaccine efficacy, 2 year average with 4 doses & $31.2 \%$ & $1.1 \%$ & $52.1 \%$ & \\
Decay parameter, $\lambda_{30}$ & -2.400 & -2.037 & -2.762 & {$[14]$} \\
Vaccine Efficacy, 2 year average with 5 doses & $50.0 \%$ & $30.0 \%$ & $70.0 \%$ & Assumed [51] \\
Decay parameter, $\lambda_{50}$ & -2.880 & -2.400 & -3.380 & Calculated [44] \\
Vaccine boosting potential, $\varrho$ & $100 \%$ & $80 \%$ & $100 \%$ & Assumed \\
PrEP Efficacy & $86 \%$ & $39.4 \%$ & $98.5 \%$ & {$[52]$} \\
\hline Disease Progression & \multicolumn{3}{c}{} & \\
\hline Probability of HIV symptoms, monthly & 0.008 & 0.000 & 0.015 & {$[30,53]$} \\
Probability of AIDS, monthly & 0.081 & 0.009 & 0.700 & {$[31]$} \\
Additional hazard of dying with HIV & 1.770 & 1.170 & 2.550 & {$[35]$} \\
AIDS mortality rate & $0.43 \%$ & $0.37 \%$ & $0.51 \%$ & {$[36]$} \\
\hline
\end{tabular}


Table 1. Cont.

\begin{tabular}{ccccc}
\hline Parameter & \multirow{2}{*}{ Value } & \multicolumn{2}{c}{ Sensitivity Ranges } & \multirow{2}{*}{ Reference } \\
\cline { 3 - 4 } & & Lower & Upper & \\
\hline Utilities & & & & \\
\hline Healthy utility, age 30-39 & 0.918 & 0.912 & 0.925 & {$[37]$} \\
Vaccine AE utility decrement & 0.003 & 0.000 & 0.005 & Assumed \\
PrEP AE utility decrement & 0.008 & 0.000 & 0.020 & Assumed \\
HIV Utility, CD4 $>500$ & 0.798 & 0.696 & 0.900 & {$[30,38,40]$} \\
HIV Utility, CD4 200-500 & 0.780 & 0.767 & 0.793 & {$[30,38,40]$} \\
AIDS Utility, CD4 <200 & 0.702 & 0.567 & 0.837 & {$[30,38,40]$} \\
\hline Costs ${ }^{1}$ & & & & \\
\hline Vaccine Price, per dose & $\$ 500$ & $\$ 100$ & $\$ 1000$ & Assumed \\
PrEP drug cost, 30-day supply & $\$ 1646$ & $\$ 893$ & $\$ 2000$ & {$[13,49]$} \\
PrEP visit cost, including lab tests & $\$ 208$ & $\$ 156$ & $\$ 260$ & {$[19]$} \\
HIV Care if CD4 $>500$, monthly & $\$ 1634$ & $\$ 1579$ & $\$ 1689$ & {$[48]$} \\
ART drug cost & $\$ 1211$ & $\$ 1172$ & $\$ 1251$ & {$[48]$} \\
Outpatient costs & $\$ 45$ & $\$ 43$ & $\$ 47$ & {$[48]$} \\
Other costs & $\$ 378$ & $\$ 364$ & $\$ 392$ & {$[48]$} \\
ART drug cost & $\$ 1924$ & $\$ 1817$ & $\$ 2032$ & {$[48]$} \\
Outpatient costs & $\$ 1158$ & $\$ 1103$ & $\$ 1212$ & {$[48]$} \\
Other costs & $\$ 54$ & $\$ 51$ & $\$ 57$ & {$[48]$} \\
HIV Care, CD4 $200-500$, monthly & $\$ 713$ & $\$ 663$ & $\$ 763$ & {$[48]$} \\
ART drug cost & $\$ 2558$ & $\$ 2334$ & $\$ 2783$ & {$[48]$} \\
Outpatient costs & $\$ 1162$ & $\$ 1094$ & $\$ 1229$ & {$[48]$} \\
Other costs & $\$ 62$ & $\$ 58$ & $\$ 67$ & {$[48]$} \\
HIV Care, CD4 $<200$, monthly & $\$ 1334$ & $\$ 1182$ & $\$ 1486$ & {$[48]$} \\
\hline
\end{tabular}

${ }^{1}$ Costs are presented in 2015 US dollars. Abbreviations: AE, adverse event; AWP, average wholesale price; ART, antiretroviral therapy; MSM, men who have sex with men; PrEP, preexposure prophylaxis.

PrEP users incurred costs from quarterly clinic visits with an HIV antibody test, other sexually transmitted infections diagnostic tests, and the measurement of blood urea nitrogen and serum creatinine levels. PrEP drugs cost $\$ 1646$ per month, based on the average wholesale price for a 30-day supply of Truvada ${ }^{\circledR}$ in 2015 [13]. As the launch price for an HIV vaccine is unknown, we benchmarked on the price per dose of other FDA-approved vaccines to prevent other sexually transmitted infections [49] and consulted expert opinion. We assumed an HIV vaccine launch price of $\$ 500$ per dose, totaling $\$ 2500$ for the five-dose series. The cost per vaccine dose ranged from $\$ 100-\$ 1000$ in the sensitivity analysis.

\subsection{Model Outputs}

The hypothetical cohort of men was followed from the time of intervention until death. Patient outcomes are reported as per-person averages, and include lifetime discounted healthcare costs, lifetime probability of HIV infection, expected life years (LYs), and expected quality-adjusted life years (QALYs). To reflect both the length and quality of life, QALYs were calculated as the sum of the monthly survival time multiplied by the utility value for the corresponding health state. Total costs and QALYs are discounted 3\% annually to reflect preferences for present as compared to future gains, also known as opportunity cost, following the guidelines from the Second US Panel on Cost-Effectiveness [54,55].

\subsection{Cost-Effectiveness Analysis}

For the primary economic endpoint, we estimated the incremental cost-effectiveness ratio (ICER) for each scenario using the equation

$$
\mathrm{ICER}=\frac{\text { Costs }_{\text {intervention }}-\text { Costs }_{\text {standard care }}}{\text { QALY }_{\text {intervention }}-\text { QALY }_{\text {standard care }}} .
$$


To interpret cost-effectiveness, we defined a cost-effectiveness threshold for the US health care payer with an assumed willingness to pay for health gains. Consistent with recommendations from the Second Panel on Cost-Effectiveness in Health and Medicine and several pharmaceutical value frameworks, we interpret ICERs <\$50,000/QALY as highly cost-effective, \$50,000-\$150,000/QALY as cost-effective, and $>\$ 150,000 / Q A L Y$ as unlikely to be cost-effective, given a threshold of 1-3 times the gross domestic product (GDP) per capita in the U.S. [28,56]. If an intervention strategy had a lower ICER and greater total health gains, it ruled out the less cost-effective strategies by "extended dominance" [57]. HIV incidence and HIV vaccine price varied in threshold analyses to identify the maximum value at which the strategy remained cost-effective when all other parameter values remain fixed. As a secondary economic endpoint, the incremental cost per HIV infection averted was estimated for each strategy.

\subsection{Sensitivity Analysis}

One-way (univariate) sensitivity analyses were performed using the upper and lower ranges of each input, holding all other variables constant, to explore the model's sensitivity to uncertainty in individual parameters (Table 1). We explored more than 500 scenarios to evaluate policy relevant cases of interest to decision-makers. Scenarios projected impacts at varying ages for the initiation of each intervention, lengths of PrEP duration, levels of PrEP adherence, and frequency of vaccine boosting. A sub-group analysis estimated the cost-effectiveness of the interventions for high-risk MSM.

A multivariate probabilistic sensitivity analysis (PSA) evaluated the combined parameter uncertainty in the model. We selected and fitted distributions for each model parameter and followed gamma for costs, beta for utilities, and normal for risk reduction using the method of moments. Monte Carlo simulations generated a unique set of input values based on random draws from these distributions and re-estimation of model outcomes as 1000 simulations per strategy.

\section{Results}

\subsection{Base Case}

\subsubsection{Clinical Outcomes}

The cohort with standard preventive care (no PrEP or HIV vaccine) had a lifetime HIV risk of 171 cases/1000 MSM (see black line in the lower panel of Figure 2). Delivering PrEP for five years reduced the lifetime risk of HIV by $25 \%$ and gained an average 0.38 lifetime QALYs per person (Table 2). HIV vaccines alone (with waning immunity with an average 50\% VE over 3 years, boosting every 5 years) reduced the risk of HIV in the cohort to 88 cases $/ 1000$ men (48\% reduction compared to the standard care) and gained an additional 0.14 lifetime QALYs compared to PrEP alone (see the grey lines in Figure 2). The combination of PrEP with an HIV vaccine achieved the largest health gains and an incremental 0.19 lifetime QALYs per person (see the dark blue lines in Figure 2) compared to vaccination alone.

Table 2. Base case outcomes per MSM receiving preventative care.

\begin{tabular}{ccccc}
\hline HIV Prevention Strategy & Total Costs $^{\mathbf{1}}$ & Total QALYs & HIV Infections & ICER $^{\mathbf{2}}$ (\$/QALY) $^{\text {Q }}$ \\
\hline Standard Care & $\$ 51,926$ & 22.057 & 170.7 & Dominated \\
PrEP & $\$ 130,811$ & 22.439 & 128.7 & Dominated \\
HIV Vaccination & $\$ 30,870$ & 22.580 & 88.3 & Dominant \\
Combination: PrEP and Vaccine & $\$ 118,484$ & 22.769 & 65.8 & $\$ 463,448$ \\
\hline
\end{tabular}

${ }^{1}$ Costs presented in 2015 US $\$$ and discounted $3 \% ;{ }^{2}$ ICERs present a ratio of incremental costs to incremental QALYs as compared to the next best option. Abbreviations: ICER, incremental cost-effectiveness ratio; PrEP, preexposure prophylaxis; QALYS, quality adjusted life-years. 


\subsubsection{Costs}

HIV prevention and treatment-related healthcare for the cohort using PrEP (average duration of five years with $86 \%$ efficacy) cost an average $\$ 78,884$ more per person than the standard care over the lifetime (Table 2 and Figure 3). The HIV vaccine strategy cost \$21,057 less per person than the standard care. The combination of PrEP with vaccination cost $\$ 66,558$ more than the standard care and $\$ 12,326$ less than PrEP alone. Over time, as patients aged, the added cost of each re-vaccination had a smaller marginal return in terms of reducing anti-retroviral therapy (ART) drug costs.
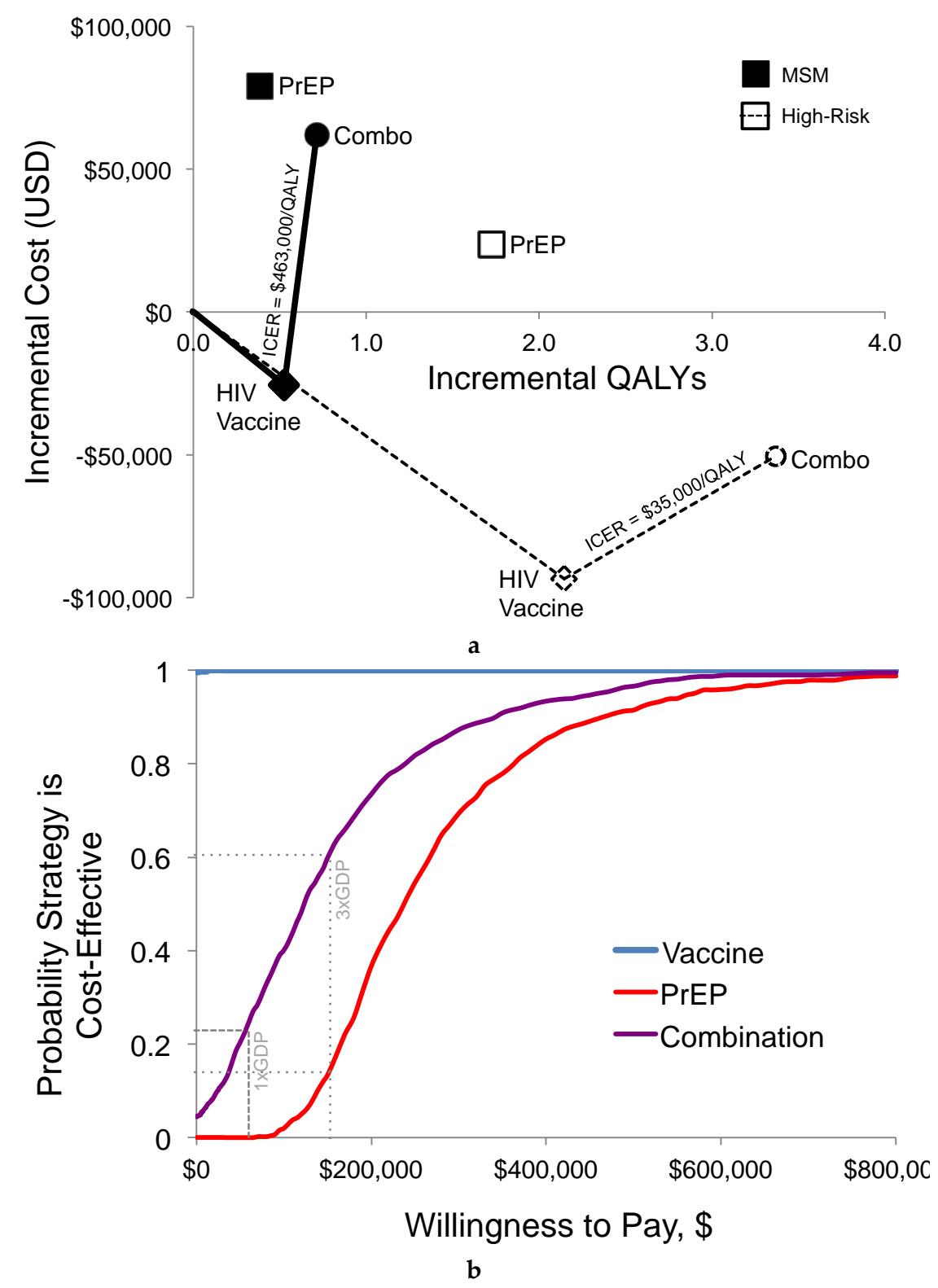

Figure 3. Cost-effectiveness results for potential prevention policies. The cost-effectiveness plane in panel (a) shows the origin representing standard preventative care, y-axes as the average incremental lifetime discounted costs per-person, and $\mathrm{x}$-axis of QALYs gained for each policy strategy as compared to standard prevention. A solid line represents the cost-effectiveness frontier for the base-case population of all MSM and a dashed line connects a high-risk scenario. Panel (b) shows results from the probabilistic sensitivity analysis as a cost-effectiveness acceptability curve. Abbreviations: QALYs, quality-adjusted life-years; ICER, incremental cost-effectiveness ratio; MSM, men who have sex with men; PrEP, pre-exposure prophylaxis. 


\subsubsection{Cost-Effectiveness}

HIV vaccination alone dominated PrEP, as the vaccine had greater health gains and lower total costs than PrEP (Table 2 and Figure 3). Vaccines dominated standard care by $\$ 40,224$ per QALY. The combination of PrEP with HIV vaccines had an ICER of $\$ 463,448$ per QALY gained, as compared to HIV vaccines alone, and would not be cost-effective even given the upper-bound threshold of $\$ 150,000$ per QALY.

\subsection{Sensitivity Analysis}

Cost-effectiveness findings were most sensitive to HIV incidence rates and PrEP drug costs in the univariate analyses (Figure 4). The cost-effectiveness of the PrEP/vaccine combination was more sensitive to the rate of decay in VE (also known as durability) than to the uncertainty in the cost or duration of PrEP. Using a threshold analysis, we estimate the maximum cost-effective price of PrEP drugs would be no more than $\$ 893$ per 30 -day supply, corresponding to a $50 \%$ reduction in the average wholesale price of Truvada ${ }^{\circledR}$ in 2015. At the largest hypothesized range of HIV vaccine price $-\$ 5000$ per series and per boost—-the vaccines resulted in lower lifetime health system costs than the standard prevention.

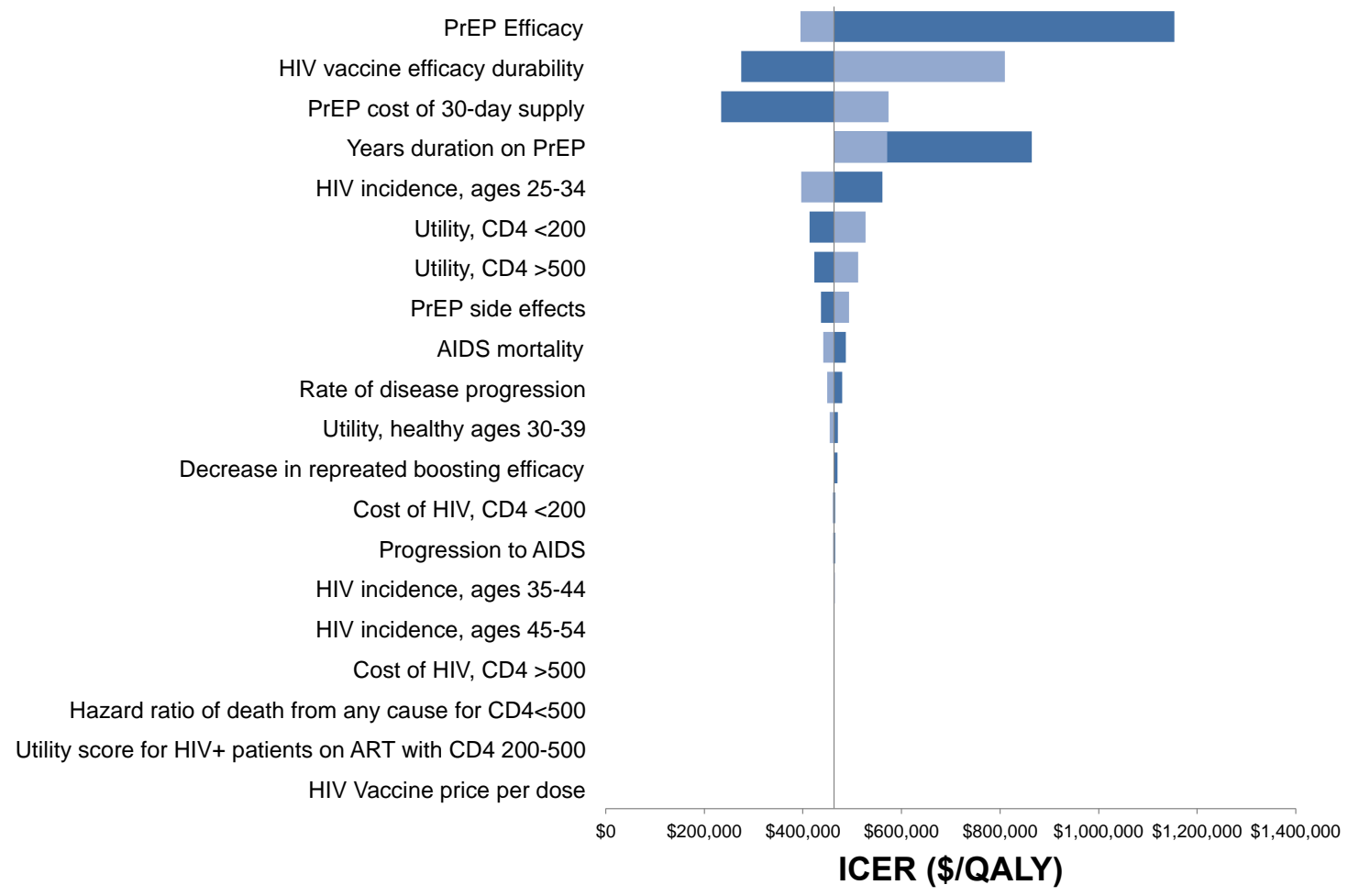

Figure 4. Tornado diagram of the one-way sensitivity analysis showing the impact of minimum and maximum parameter ranges on the ICER of the combination strategy versus HIV vaccines alone. Univariate sensitivity of the PrEP duration shows that 1 year or 10 years on PrEP in the combination strategy have larger ICERs than the base case assumption of 5 years duration, because the balance of lifetime PrEP costs and benefits is closer to the optimization of duration at 5 compared to 1 or 10 years.

\subsubsection{Scenarios}

Pairwise comparisons of policy-relevant scenarios for PrEP, HIV vaccines, and combination versus standard care are provided in a heatmap of cost-effectiveness (Figure 5). Vaccines only dominated PrEP if the HIV vaccine boosts restored a protective immunogenicity response at each injection. Vaccination without boosting gained 37\% fewer QALYs and cost 30\% more in lifetime HIV-related health care than re-boosting every 5 years. PrEP alone was cost-effective for high-risk men (with 
lifetime annual HIV incidence reaching a maximum of 8.9\%) and had an ICER of \$13,713 per QALY compared to standard prevention. With PrEP duration extended to 10 years, vaccination alone no longer dominated PrEP and it had an ICER of \$776,786/QALY compared to the standard care. In this extended use scenario, the PrEP-vaccine combination dominated PrEP alone by extension. In high-risk men, 10 years of PrEP is projected to be cost-effective with an ICER of \$64,159 per QALY vs. standard care. Figure 5 suggests that these HIV prevention interventions offer the greatest value in younger and higher-risk populations.

\section{Incremental Cost-Effectivenss Ratio}

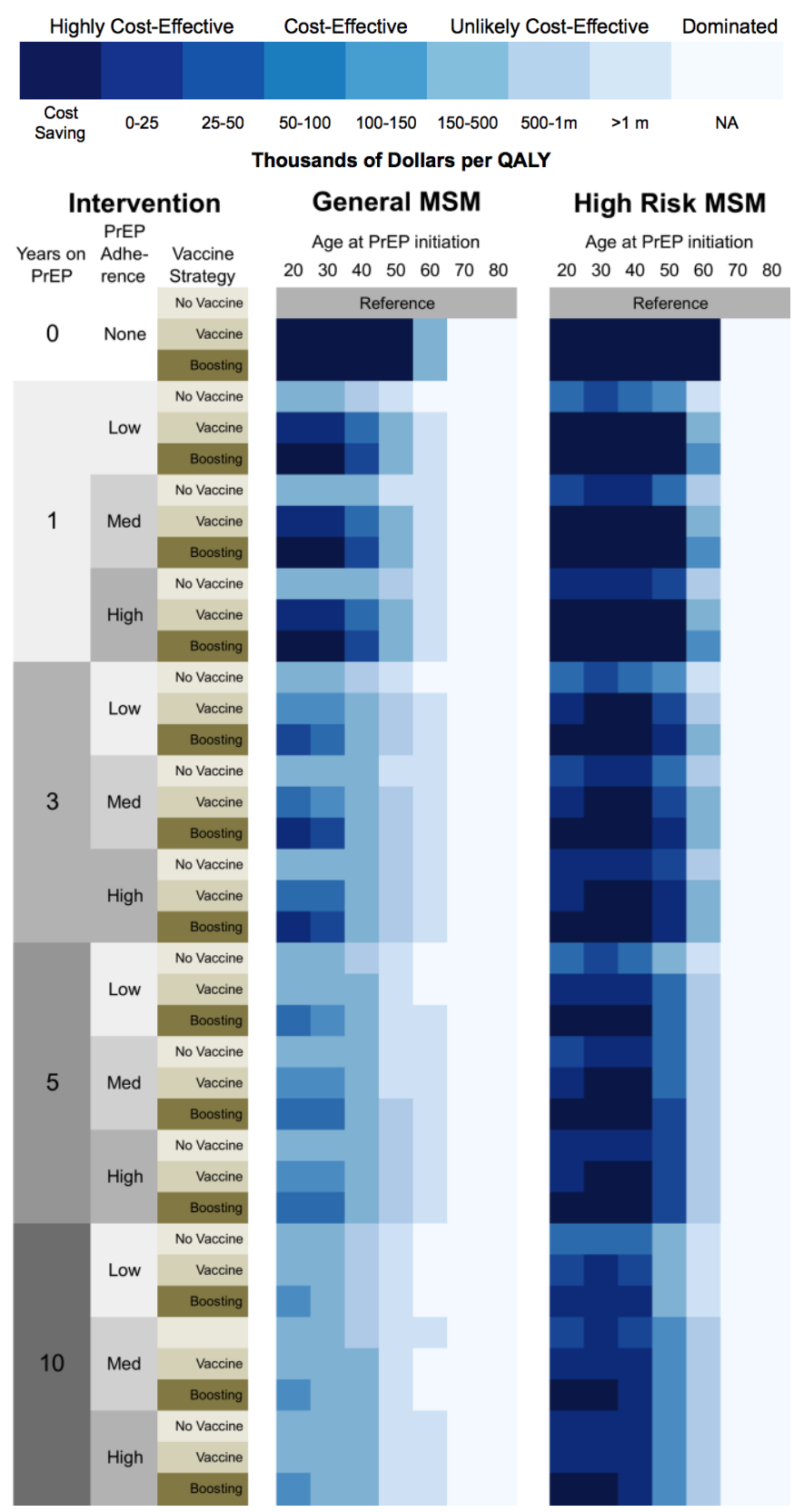

Figure 5. Sensitivity analyses of the cost-effectiveness of pairwise comparisons of scenarios versus standard care suggest that strategies would be more cost-effective with younger populations, higher-risk men, shorter duration on PrEP, and added HIV vaccine boosting. The darker blue color represents greater cost-effectiveness and the lighter color represents scenarios dominated or unlikely to be cost-effective as compared to the standard care. 


\subsubsection{Probabilistic Sensitivity Analysis}

Consistent with the deterministic findings, HIV vaccines dominated standard care and PrEP alone in the probabilistic sensitivity analysis (Figure 6). PrEP alone cost $\$ 77,895$ (95\% credible range [CR] $\$ 42,095-\$ 113,695)$ more per person than standard care and was the highest cost strategy. In comparison to HIV vaccines alone, adding PrEP for the combination strategy cost an additional $\$ 86,976$ per person (95\% CR \$52,080-\$121,853) and gained 0.19 QALYs (95\% CR -0.06-0.44) per person on average. We estimated an average ICER of $\$ 696,318$ per QALY (95\% CR of $-\$ 584,780-\$ 2$ million) for the combination strategy versus HIV vaccines alone. The distribution of simulations in each strategy shows a shift in the distribution of simulations down (lower costs) and to the right (greater health) for the combination compared to PrEP alone.

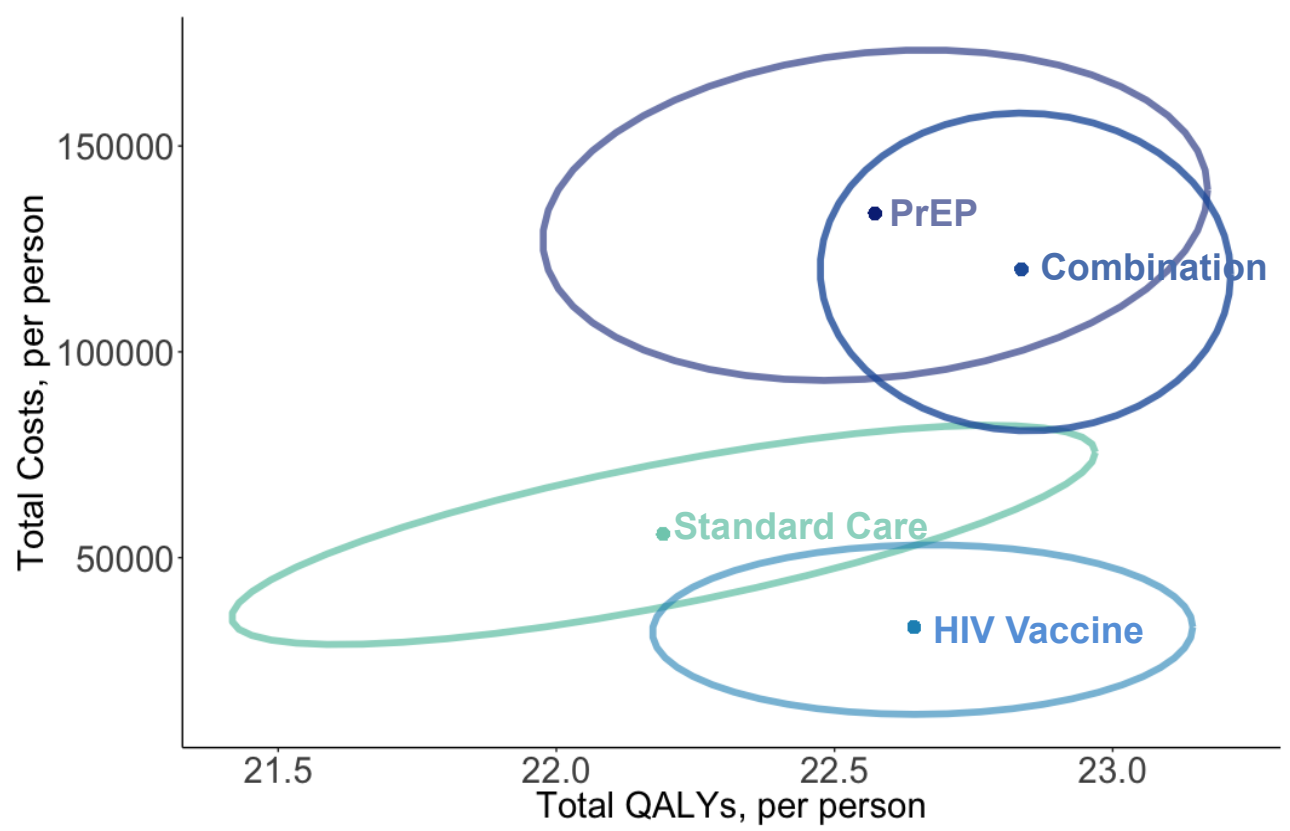

Figure 6. Distribution of incremental costs and QALYs per person among 1000 Monte Carlo simulations in the probabilistic sensitivity analysis. The ellipse represents $95 \%$ credible ranges around the average estimate for each strategy.

\section{Discussion}

We projected the potential cost-effectiveness of HIV prevention strategies for MSM in the US after the future introduction of HIV vaccines. We found that HIV vaccination dominated PrEP alone (i.e., increased QALYs and reduced costs). A combination of PrEP with HIV vaccines provided the highest total QALYs but with substantial additional costs versus the other interventions: and it was unlikely to be cost-effective. However, the sensitivity analyses suggest that the combination strategy may be cost-effective for high-risk men provided the estimates for vaccine effectiveness from previous trials remain consistent in the ongoing pivotal trials. PrEP alone is not projected to be cost-effective in general MSM at the current PrEP prices.

PrEP costs too much to be cost-effective at the current prices. Potential options for PrEP to be cost-effective could include discounting the price by $50 \%$, supported by findings of the threshold analysis, restricting the indication to higher-risk men, introduction of indication-specific pricing, or the entry of generic PrEP medications. Indication-specific pricing could accommodate one value-based charge and reimbursement for Truvada ${ }^{\circledR}$ prescribed for HIV treatment and a second, lower, value-based price for Truvada ${ }^{\circledR}$ prescribed for prevention [58]. If implemented, a larger population would be recommended for the cost-effective use of PrEP and HIV vaccines in combination. The anticipated 
reduction in PrEP costs with generic drug entry may be delayed if the recently approval drug tenofovir alafenamide fumarate (TAF, trade name Descovy ${ }^{\circledR}$, Gilead Sciences Inc., Foster City, CA, USA) replaces TDF for PrEP. TAF may effectively extend the patent-life of Truvada ${ }^{\circledR}$, capture new users, and help Gilead maintain its large market share of HIV drugs even after generic entry of TDF. Even if PrEP drugs were "free" for PrEP patients, the costs of implementation with quarterly clinic visits and STI diagnostic panels could substantially impact community clinic budgets. These results inform drug developers and suggest that long-acting injectable PrEP formulations could lower implementation costs with formulations capable of lasting greater than three months.

HIV vaccine success relies on either the durability of protection or the potential for boosting years later to elicit robust immunogenicity responses that correlate strongly with protection from infection. If PrEP drug costs are lowered, future HIV vaccine clinical trial designs may consider increasing sample sizes to evaluate the combined safety, efficacy, and potential synergy of HIV vaccines administered with PrEP. If HIV vaccines can more effectively reach disproportionately affected high-risk groups with little PrEP use, such as young Black and Latino MSM in the Southeastern United States [59], the availability of both products could substantially impact HIV incidence. Efficient implementation, defined as achieving the greatest health benefits under constrained healthcare resources, may be achieved through the recommendation of HIV vaccines for all MSM and PrEP for only some. The scenarios' analysis informs vaccine research and development strategies with evidence that a moderately effective boosting dose could increase the potential market size for cost-effective administration by broadening the recommended target population from at-risk to the general population, and as a consequence increase potential revenue.

Our estimates for the cost-effectiveness of PrEP and HIV vaccines alone are consistent with results from other models including dynamic transmission models [21,60]. The PrEP-alone cost-effectiveness findings align with Juusola et al., who estimated PrEP for all MSM costs $\$ 216,480$ per QALY gained (differing by $5 \%$ from our ICER for this population) [19]. Similarly, PrEP for injection drug users in the US was estimated by Bernard et al. to cost $\$ 253,000$ per QALY gained [20]. For HIV vaccines alone, our cost-saving projections are consistent with Long et al. in the scenarios with similar assumptions [23]. The results from this analysis differ from a recent economic analysis of Canadian MSM where PrEP was cost-saving in almost all scenarios [61]. The different result may be due to lower Canadian drug costs and the selection of HIV incidence rates, as the Canadian study applied a constant number needed to treat (NTT) from a high-risk Peruvian population with $5 \%$ annual HIV incidence, while our analysis parameterized baseline infection rates to age-specific CDC HIV incidence in the USA. In the sensitivity analysis, if annual HIV incidence was increased to the same constant $5 \%$ rate, similar conclusions would be reached for the PrEP-alone cost-effectiveness. As HIV incidence is frequently a driver of the value of HIV prevention, the different sources of baseline transmission rates in each model may explain why different analyses have reached very different conclusions.

Our analysis had a number of limitations that warrant mention. First and foremost is the hypothetical nature of the efficacy estimates and attrition rates for long-term vaccine boosting and the combination of PrEP with vaccines. We considered a healthcare payer perspective and therefore did not include transmission dynamics to capture the indirect benefits of vaccination to others. As a consequence, our results are likely to underestimate the population-level health benefits from the prevention interventions. While the results of a dynamic population model can inform societal benefits over time, this study informs an individual patient or physician about the added costs and average gain in life expectancy and quality of life one 30-year-old man might gain over their lifetime if they choose to use PrEP and/or choose to be vaccinated. The model inputs are specific to the US and the results and conclusions are not transferrable to other settings. Considering the sensitivity of results to drug prices and HIV incidence, and how the values can differ greatly between countries, the cost-effectiveness of HIV vaccine and PrEP combinations should be analyzed for other settings using local inputs. The current incidence of HIV in MSM recommended to take PrEP is unknown, but we address this by scaling feasible ranges based on age trends in published data $[32,62,63]$. The model also 
assumes no behavioral disinhibition among intervention users, meaning an individual's perception of protection from HIV will not lead them to increase risky choices. Future modeling studies should examine HIV vaccine uptake and the potential impact of the interaction with PrEP utilization as a complement or substitute.

\section{Conclusions}

Balancing the high cost and high effectiveness of PrEP with the potentially low cost and moderate effectiveness of HIV vaccines calls for the innovative design and testing of these products if combinations are planned for implementation. Achieving the ambitious milestones in the National Strategic Plan for the USA requires efficient spending of limited health care resources and research dollars. Early identification of high-value vaccine candidates and planning for optimal combinations with PrEP could extend many lives and reduce the burden of HIV in the USA.

Acknowledgments: Blythe J. S. Adamson is supported by grant number T32HS013853 from the Agency for Healthcare Research and Quality, a fellowship from the American Foundation for Pharmaceutical Education (AFPE), and a Trainee Support Grant from the University of Washington Center for AIDS Research (CFAR), an NIH funded program under award number P30AI027757. James G. Kublin is the Executive Director of the HIV Vaccine Trials Network and leads clinical trials of HIV vaccine candidates, supported by the National Institute of Allergy and Infectious Diseases (NIAID) U.S. Public Health Service Grants UM1 AI068614. Thanks to Gillian Sanders for advice on modeling HIV cost-effectiveness in the United States and Ruanne Barnabas and Dobromir Dimitrov for instruction on modeling HIV and PrEP combinations. We would like to acknowledge guidance from Walensky et al. [64] as a framework for the design of the tables, figures, and text structure. Annie Pezalla provided technical editing.

Author Contributions: Blythe J. S. Adamson, Louis P. Garrison, Jr., James G. Kublin, and Josh J. Carlson conceived and designed the experiments; Blythe J. S. Adamson developed the mathematical model and performed the analysis; Blythe J. S. Adamson, Louis P. Garrison, Jr., James G. Kublin, and Josh J. Carlson interpreted the results; Blythe J. S. Adamson and Josh J. Carlson drafted the paper; Blythe J. S. Adamson, Louis P. Garrison, Jr., James G. Kublin, and Josh J. Carlson edited and revised the paper.

Conflicts of Interest: The authors declare no conflict of interest. The content is solely the responsibility of the authors and does not necessarily represent the official views of the Agency for Healthcare Research and Quality or the National Institutes of Health. The founding sponsors had no role in the design of the study; in the collection, analyses, or interpretation of data; in the writing of the manuscript, and in the decision to publish the results.

\section{Abbreviations}

The following abbreviations and corresponding units are used in this manuscript:

$\begin{array}{ll}\text { ART } & \text { Antiretroviral Therapy } \\ \text { AWP } & \text { Average Wholesale Price, \$ } \\ \text { CEA } & \text { Cost-Effectiveness Analysis } \\ \text { CPI } & \text { Consumer Price Index } \\ \text { CR } & \text { Credible Range } \\ \text { FTC } & \text { emtricitabine } \\ \text { ICER } & \text { Incremental Cost Effectiveness Ratio, \$/QALY } \\ \text { LY } & \text { Life Years } \\ \text { MSM } & \text { Men Who Have Sex With Men } \\ \text { NNT } & \text { Number Needed To Treat } \\ \text { PrEP } & \text { Pre-exposure Prophylaxis } \\ \text { PSA } & \text { Probabilistic Sensitivity Analysis } \\ \text { QALY } & \text { Quality-Adjusted Life Year } \\ \text { TAF } & \text { tenofovir alafenamide fumarate } \\ \text { TDF } & \text { tenofovir disoproxil fumarate } \\ \text { USA } & \text { United States of America } \\ \text { VE } & \text { Vaccine Efficacy, \% } \\ \text { WTP } & \text { Willingness to Pay, \$ }\end{array}$




\section{Appendix A}

Table A1. Description of HIV vaccine candidates in clinical trials.

\begin{tabular}{|c|c|c|c|c|c|c|}
\hline \multirow{2}{*}{ Vaccine Component } & \multicolumn{3}{|c|}{ RV144 Thai Trial } & \multicolumn{3}{|c|}{ HVTN 702 South Africa Trial } \\
\hline & DNA Prime & Protein Boost & Adjuvant & DNA Prime & Protein Boost & Adjuvant \\
\hline Description & $\begin{array}{c}\text { ALVAC-HIV recombinant } \\
\text { canarypox vaccine, subtype B } \\
\text { and E }\end{array}$ & $\begin{array}{l}\text { AIDSVAX }{ }^{\circledR} \text { B/E bivalent HIV } \\
\text { gp120 envelope glycoprotein } \\
\text { vaccine, subtypes B and E }\end{array}$ & $\begin{array}{l}600 \mu \mathrm{g} \text { of alum } \\
\text { adjuvant }\end{array}$ & $\begin{array}{c}\text { Canarypox-based } \\
\text { vaccine ALVAC-HIV } \\
\text { subtype C }\end{array}$ & $\begin{array}{c}\text { bivalent gp120 } \\
\text { protein subunit } \\
\text { vaccine, subtype } C\end{array}$ & MF59 \\
\hline Manufacturer & $\begin{array}{l}\text { Developed by Virogenetics } \\
\text { Corporation (Troy, NY) and } \\
\text { manufactured by Sanofi Pasteur } \\
\text { (Marcy-l'Étoille, France) }\end{array}$ & $\begin{array}{l}\text { Originally manufactured by } \\
\text { Genentech, Inc., further } \\
\text { developed by VaxGen, Inc., later } \\
\text { acquired by Global Solutions for } \\
\text { Infectious Diseases (San } \\
\quad \text { Francisco, CA, USA) }\end{array}$ & VaxGen, Inc, no IP & Sanofi Pasteur & $\begin{array}{l}\text { GlaxoSmithKline } \\
\text { (GSK) }\end{array}$ & GSK \\
\hline Trial Funding & \multicolumn{3}{|c|}{$\begin{array}{l}\text { Supported in part by an Interagency Agreement (Y1-AI-2642-12) between the U.S. Army } \\
\text { Medical Research and Materiel Command and the National Institute of Allergy and Infectious } \\
\text { Diseases and by a cooperative agreement (W81XWH-07-2-0067) between the Henry M. Jackson } \\
\text { Foundation for the Advancement of Military Medicine and the U.S. Department of Defense. } \\
\text { Sanofi Pasteur provided the ALVAC-HIV vaccine, and Global Solutions for Infectious Diseases } \\
\text { (VaxGen) provided the reagents for the immunogenicity assays. }\end{array}$} & \multicolumn{3}{|c|}{$\begin{array}{l}\text { P5 members are National Institute of Allergy and Infectious } \\
\text { Diseases (NIAID), the Bill \& Melinda Gates Foundation (BMGF), } \\
\text { the South African Medical Research Council (SAMRC), HIV } \\
\text { Vaccine Trials Network (HVTN), Sanofi Pasteur, GSK, and the U.S. } \\
\text { Military HIV Research Program. NIAID, BMGF, and SAMRC fund } \\
\text { the P5. The National Institute of Allergy and Infectious Diseases } \\
\text { (NIAID) is sponsoring and funding HVTN 702. Sanofi Pasteur and } \\
\text { GSK are providing the investigational vaccines for the trial. }\end{array}$} \\
\hline
\end{tabular}


Table A2. Impact inventory.

\begin{tabular}{|c|c|c|c|c|}
\hline \multirow{2}{*}{ Sector } & \multirow{2}{*}{ Type of Impact (Unit of Measure if Relevant) } & \multicolumn{3}{|c|}{ Included in this Analysis from the Perspective of } \\
\hline & & Payer $\square$ & Health Care Sector & Societal \\
\hline \multirow{12}{*}{$\begin{array}{l}\text { Formal } \\
\text { Health-care sector }\end{array}$} & Health Outcomes (Effects) & & & \\
\hline & Longevity effects (Life Years) & $\square$ & & \\
\hline & Health-related quality of life (QALYs) & $\square$ & & \\
\hline & Adverse events (QALYS) & $\emptyset$ & & \\
\hline & Secondary transmissions of infections & & & \\
\hline & Medical Costs & & & \\
\hline & Paid for by third-party payers (\$) & $\square$ & & \\
\hline & Paid for by patients out-of-pocket (\$) & & & \\
\hline & Future related medical costs to payers (\$) & $\square$ & & \\
\hline & Future related medical costs to patients (\$) & NA & & \\
\hline & Future unrelated medical costs to payers $(\$)$ & & & \\
\hline & Future unrelated medical costs to patients (\$) & NA & & \\
\hline \multirow{3}{*}{$\begin{array}{l}\text { Informal } \\
\text { Health-care sector }\end{array}$} & Patient time costs & NA & & \\
\hline & Unpaid caregiver time costs $(\$)$ & NA & & \\
\hline & Transportation costs (\$) & NA & & \\
\hline \multirow{3}{*}{ Productivity } & Labor market earnings lost (\$) & NA & NA & \\
\hline & Cost of unpaid lost productivity due to illness (\$) & NA & NA & \\
\hline & Cost of uncompensated household production (\$) & NA & NA & \\
\hline Consumption & Future consumption unrelated to health (\$) & NA & NA & \\
\hline Social Services & Cost of social services as part of intervention (\$) & NA & NA & \\
\hline Education & $\begin{array}{l}\text { Impact of intervention on educational } \\
\text { achievement of population }\end{array}$ & NA & NA & \\
\hline
\end{tabular}

Abbreviation: NA, not applicable; QALYs, quality-adjusted life years.

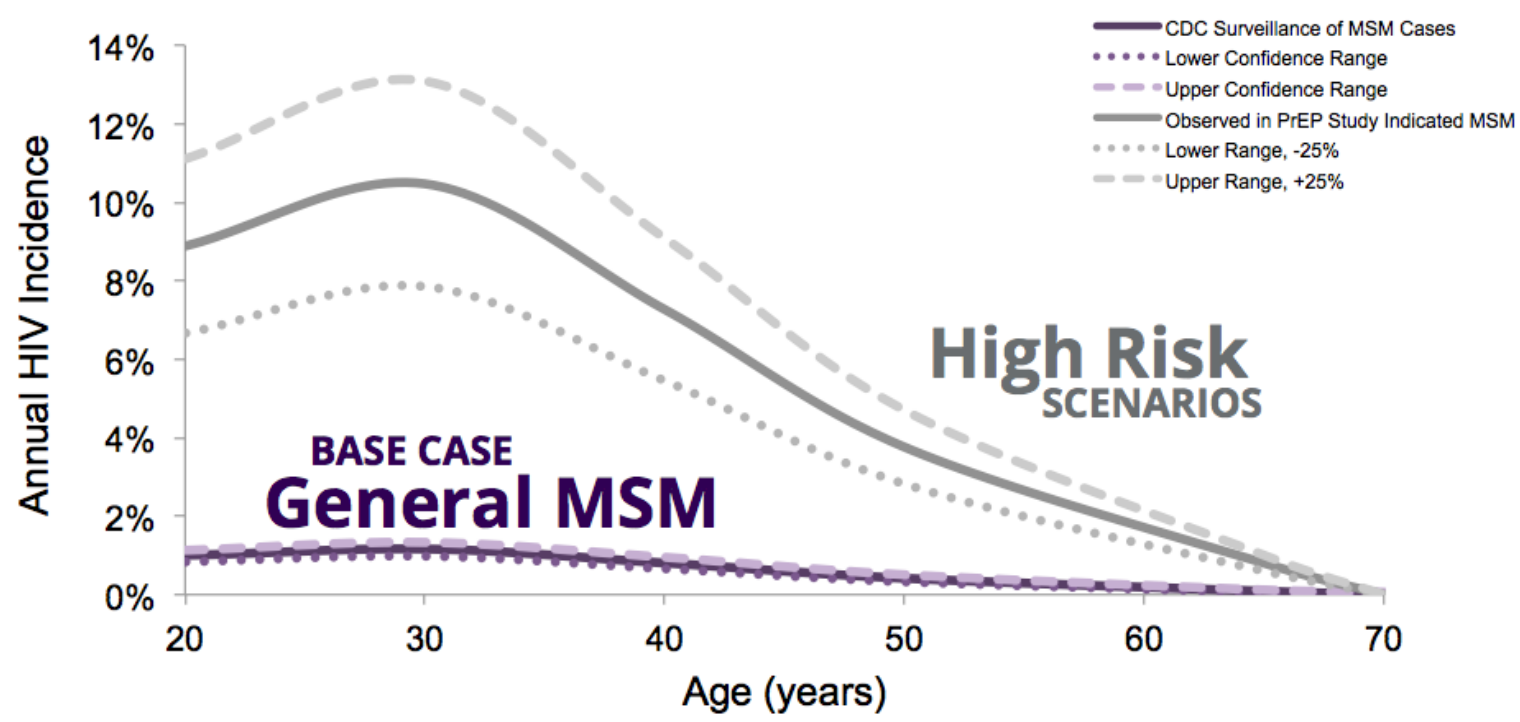

Figure A1. Incident HIV infections among men-who-have-sex-with-men (MSM) in the United States, based on 2012 CDC surveillance data [32]. 


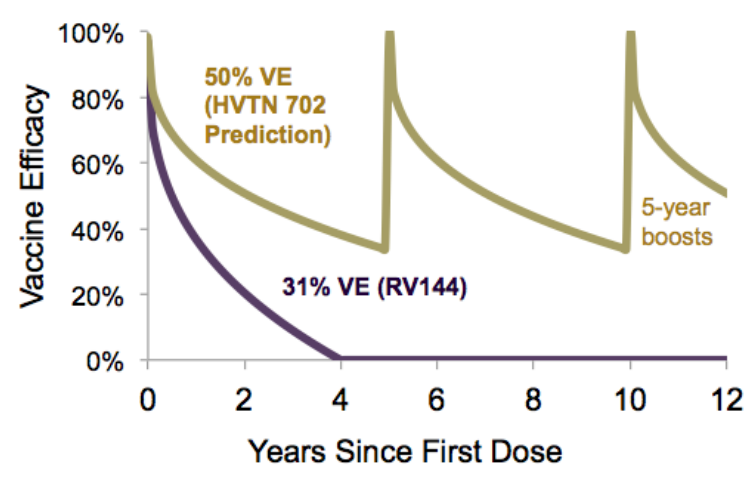

(a)

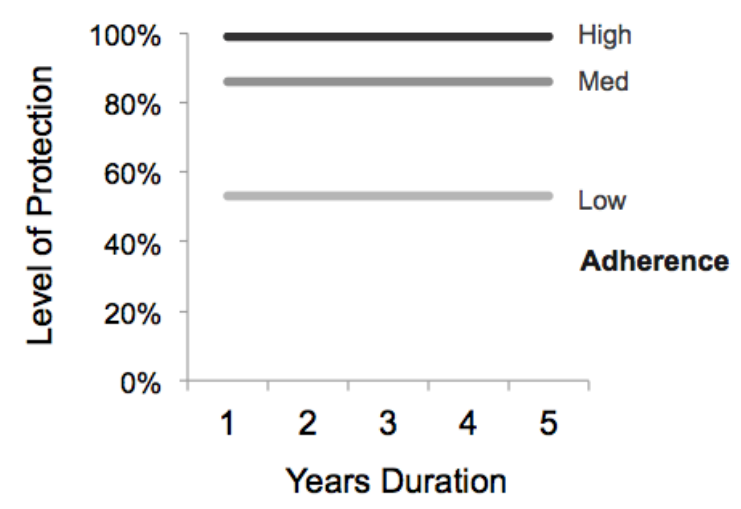

(b)

Figure A2. Percent reduction in HIV infection for HIV vaccines and PrEP as modeled in the analysis. Intervention efficacy assumptions for (a) HIV vaccine efficacy decaying over time with boosting every 5 years and (b) PrEP by the level of adherence. Abbreviations: PrEP, Pre-exposure prophylaxis; VE, vaccine efficacy.

\section{Model Validation}

We compared the mean total remaining life years for the cohort and compared this to the life expectancy of U.S. men. To support validation of the selected transition probabilities for HIV progression, we initialized HIV disease compartments with a cohort of newly infected patients and calculated the average remaining life-years. We subtracted this number from the average total life years for a scenario with no HIV infections and compared the difference to the estimated life years lost from HIV infection calculated by others. We validated the costs by comparing our estimated average cost of HIV care per infection to the lifetime cost of HIV calculated by Franham in 2013 and Schackman in 2015 [65,66].

\section{References}

1. Holtgrave, D.R.; Hall, H.I.; Wehrmeyer, L.; Maulsby, C. Costs, consequences and feasibility of strategies for achieving the goals of the National HIV/AIDS strategy in the United States: A closing window for success? AIDS Behav. 2012, 16, 1365-1372. [CrossRef] [PubMed]

2. Farnham, P.G.; Holtgrave, D.R.; Gopalappa, C.; Hutchinson, A.B.; Sansom, S.L. Lifetime costs and quality-adjusted life years saved from HIV prevention in the test and treat era. J. Acquir. Immune Defic. Syndr. 2013, 64, 15-18. [CrossRef] [PubMed]

3. Schackman, B.R.; Gebo, K.A.; Walensky, R.P.; Losina, E.; Muccio, T.; Sax, P.E.; Weinstein, M.C.; Seage, G.R.; Moore, R.D.; Freedberg, K.A. The lifetime cost of current human immunodeficiency virus care in the United States. Med. Care 2006, 44, 990-997. [CrossRef] [PubMed]

4. The Henry J. Kaiser Family Foundation. U.S. Federal Funding for HIV/AIDS: Trends Over Time; The Henry J. Kaiser Family Foundation: Menlo Park, CA, USA, 2016.

5. Jiang, J.; Yang, X.; Ye, L.; Zhou, B.; Ning, C.; Huang, J.; Liang, B.; Zhong, X.; Huang, A.; Tao, R.; et al. Pre-exposure prophylaxis for the prevention of HIV infection in high risk populations: A meta-analysis of randomized controlled trials. PLoS ONE 2014, 9, e87674. [CrossRef] [PubMed]

6. Liu, A.; Glidden, D.V.; Anderson, P.L.; Amico, K.R.; McMahan, V.; Mehrotra, M.; Lama, J.R.; MacRae, J.; Hinojosa, J.C.; Montoya, O; et al. Patterns and correlates of PrEP drug detection among MSM and transgender women in the global iPrEx study. J. Acquir. Immune Defic. Syndr. 2014. [CrossRef] [PubMed]

7. Molina, J.M.; Capitant, C.; Spire, B.; Pialoux, G.; Cotte, L.; Charreau, I.; Tremblay, C.; Gall, J.M.L.; Cua, E.; Pasquet, A.; et al. On-demand preexposure prophylaxis in men at high risk for HIV-1 infection. N. Engl. J. Med. 2015, 373, 2237-2246. [CrossRef] [PubMed]

8. McCormack, S.; Dunn, D. Pragmatic open-label randomised trial of preexposure prophylaxis: The PROUD study. In Proceedings of the Conference Retroviruses Opportunistic Infect, Seattle, WA, USA, 23-26 February 2015. 
9. Volk, J.E.; Marcus, J.L.; Phengrasamy, T.; Blechinger, D.; Nguyen, D.P.; Follansbee, S.; Hare, C.B. No new HIV infections with increasing use of HIV preexposure prophylaxis in a clinical practice setting. Clin. Infect. Dis. 2015, 61, civ778. [CrossRef] [PubMed]

10. Express Scripts 2015 Drug Trend Report. Available online: https://www.google.ch / url? sa=t\&rct=j\&q=\&esrc= s\&source=web\&cd=2\&sqi=2\&ved=0ahUKEwiKoZG-4IXUAhVLFMAKHemUAPQQFgguMAE\&url= https\%3A\%2F\%2Flab.express-scripts.com\%2Flab\%2F \%2Fmedia\%2Fe2c9d19240e94fcf893b706e13068750. ashx\&usg=AFQjCNF8GLkNH0aNfbFjCynKBkO3DH_19Q\&cad=rja (accessed on 13 November 2016).

11. Smith, D.K.; van Handel, M.; Wolitski, R.J.; Stryker, J.E.; Hall, H.I.; Prejean, J.; Koenig, L.J.; Valleroy, L.A. Vital signs: Estimated percentages and numbers of adults with indications for preexposure prophylaxis to prevent hiv acquisition-United States, 2015. MMWR 2015, 64, 1291-1295. [CrossRef] [PubMed]

12. Grey, J.A.; Bernstein, K.T.; Sullivan, P.S.; Purcell, D.W.; Chesson, H.W.; Gift, T.L.; Rosenberg, E.S. Estimating the population sizes of men who have sex with men in US States and counties using data from the american community survey. JMIR Public Health Surveill 2016, 2, e14. [CrossRef] [PubMed]

13. Basow, D.S. Tenofovir Disoproxil Fumarate and Emtricitabine: Drug Information; UpToDate: Waltham, MA, USA, 2015.

14. Rerks-Ngarm, S.; Pitisuttithum, P.; Nitayaphan, S.; Kaewkungwal, J.; Chiu, J.; Paris, R.; Premsri, N.; Namwat, C.; de Souza, M.; Adams, E.; et al. Vaccination with ALVAC and AIDSVAX to prevent HIV-1 infection in Thailand. N. Engl. J. Med. 2009, 361, 2209-2220. [CrossRef] [PubMed]

15. Akapirat, S.; Chitraporn, K.; O'Connell, R.J.; Pitisuthithum, P.; Rerks-Ngarm, S.; Michael, N.L.; De Souza, M.A.; Kim, J.H.; Karasavvas, N. Antibody responses in anogenital secretions of rv305 a late boost vaccination of RV144 volunteers. In Proceedings of the Retroviruses Opportunistic Infect, Boston, MA, USA, 3-6 March 2014; pp. 3-6.

16. National Institute of Allergy and Infectious Diseases. Large-Scale HIV Vaccine Trial to Launch in South Africa: NIH-Funded Study Will Test Safety, Efficacy of Vaccine Regimen. NIH News 2016. Available online: https:/ / www.niaid.nih.gov/news-events/large-scale-hiv-vaccine-trial-launch-south-africa (accessed on 13 November 2016).

17. Abbasi, J. Large HIV vaccine trial launches in South Africa. JAMA 2017, 317, 350. [CrossRef] [PubMed]

18. Paltiel, A.D.; Freedberg, K.A.; Scott, C.A.; Schackman, B.R.; Losina, E.; Wang, B.; Seage, G.R., 3rd; Sloan, C.E.; Sax, P.E.; Walensky, R.P. HIV preexposure prophylaxis in the United States: Impact on lifetime infection risk, clinical outcomes, and cost-effectiveness. Clin. Infect. Dis. 2009, 48, 806-815. [CrossRef] [PubMed]

19. Juusola, J.L.; Brandeau, M.L.; Owens, D.K.; Bendavid, E. The cost-effectiveness of preexposure prophylaxis for HIV prevention in the United States in men who have sex with men. Ann. Intern. Med. 2012, 156, 541-550. [CrossRef] [PubMed]

20. Bernard, C.L.; Brandeau, M.L.; Humphreys, K.; Bendavid, E.; Holodniy, M.; Weyant, C.; Owens, D.K.; Goldhaber-Fiebert, J.D. Cost-effectiveness of HIV preexposure prophylaxis for people who inject drugs in the United States. Ann. Intern. Med. 2016, 165, 10-19. [CrossRef] [PubMed]

21. Gomez, G.B.; Borquez, A.; Case, K.K.; Wheelock, A.; Vassall, A.; Hankins, C. The cost and impact of scaling up pre-exposure prophylaxis for HIV prevention: A systematic review of cost-effectiveness modelling studies. PLoS Med. 2013, 10, e1001401. [CrossRef] [PubMed]

22. Long, E.F.; Brandeau, M.L.; Owens, D.K. Potential population health outcomes and expenditures of HIV vaccination strategies in the United States. Vaccine 2009, 27, 5402-5410. [CrossRef] [PubMed]

23. Long, E.F.; Owens, D.K. The cost-effectiveness of a modestly effective HIV vaccine in the United States. Vaccine 2011, 29, 6113-6124. [CrossRef] [PubMed]

24. Adamson, B.; Dimitrov, D.; Devine, B.; Barnabas, R. The potential cost-effectiveness of HIV vaccines: A systematic review. Pharmacoeconomics 2017, 1-12. [CrossRef] [PubMed]

25. Schackman, B.R.; Eggman, A.A. Cost-effectiveness of pre-exposure prophylaxis for HIV: A review. Curr. Opin. HIV AIDS 2012, 7, 587-592. [CrossRef] [PubMed]

26. Hankins, C.A. Untangling the cost-effectiveness knot: Who is oral antiretroviral HIV pre-exposure prophylaxis really for? Expert Rev. Pharm. Outcomes Res. 2014, 14, 167-170. [CrossRef] [PubMed]

27. US Public Health Service. Preexposure Prophylaxis For The Prevention Of HIV Infection In The United States-2014: A Clinical Practice Guideline; US Public Health Service: Atlanta, GA, USA, 2014.

28. Neumann, P.J.; Sanders, G.; Russell, L.; Siegel, J.; Ganiats, T. Cost-Effectiveness in Health and Medicine, 2nd ed.; Oxford University Press: New York, NY, USA, 2017. 
29. Husereau, D.; Drummond, M.; Petrou, S.; Carswell, C.; Moher, D.; Greenberg, D.; Augustovski, F.; Briggs, A.H.; Mauskopf, J.; Loder, E. Consolidated health economic evaluation reporting standards (CHEERS) statement. Int. J. Technol. Assess. Health Care 2013, 29, 117-122. [CrossRef] [PubMed]

30. Sanders, G.D.; Bayoumi, A.M.; Sundaram, V.; Bilir, S.P.; Neukermans, C.P.; Rydzak, C.E.; Douglass, L.R.; Lazzeroni, L.C.; Holodniy, M.; Owens, D.K. Cost-effectiveness of screening for HIV in the era of highly active antiretroviral therapy. N. Engl. J. Med. 2005, 352, 570-585. [CrossRef] [PubMed]

31. Bayoumi, A.M.; Barnett, P.G.; Joyce, V.R.; Griffin, S.C.; Sun, H.; Bansback, N.J.; Holodniy, M.; Sanders, G.; Brown, S.T.; Kyriakides, T.C.; et al. Cost-effectiveness of newer antiretroviral drugs in treatment-experienced patients with multidrug-resistant HIV disease. J. Acquir. Immune Defic. Syndr. 2013, 64, 382-391. [CrossRef] [PubMed]

32. Centers for Disease Control and Prevention. HIV/AIDS data through December 2012 provided for the Ryan White HIV/AIDS Program, for fiscal year 2014. HIV Surveill Suppl. Rep. 2015, 20, 1-16.

33. U.S. Census Bureau Population Division. National Population Projection, 2014; U.S. Census Bureau Population Division: Washington, DC, USA, 2015.

34. Arias, E. Division of vs. United States life tables, 2010. Natl. Vital Stat. Rep. 2014, 63, 1-62. [PubMed]

35. Rodger, A.J.; Lodwick, R.; Schechter, M.; Deeks, S.; Amin, J.; Gilson, R.; Paredes, R.; Bakowska, E.; Engsig, F.N.; Phillips, A.; et al. Mortality in well controlled HIV in the continuous antiretroviral therapy arms of the SMART and ESPRIT trials compared with the general population. AIDS 2013, 27, 973-979. [CrossRef] [PubMed]

36. Weber, R.; Ruppik, M.; Rickenbach, M.; Spoerri, A.; Furrer, H.; Battegay, M.; Cavassini, M.; Calmy, A.; Bernasconi, E.; Schmid, P.; et al. Decreasing mortality and changing patterns of causes of death in the Swiss HIV Cohort Study. HIV Med. 2013, 14, 195-207. [CrossRef] [PubMed]

37. Hanmer, J.; Lawrence, W.F.; Anderson, J.P.; Kaplan, R.M.; Fryback, D.G. Report of nationally representative values for the noninstitutionalized US adult population for 7 health-related quality-of-life scores. Med. Decis. Mak. 2006, 26, 391-400. [CrossRef] [PubMed]

38. Tengs, T.O.; Lin, T.H. A meta-analysis of utility estimates for HIV/AIDS. Med. Decis. Mak. 2002, 22, 475-481. [CrossRef] [PubMed]

39. Kauf, T.L.; Roskell, N.; Shearer, A.; Gazzard, B.; Mauskopf, J.; Davis, E.A.; Nimsch, C. A predictive model of health state utilities for HIV patients in the modern era of highly active antiretroviral therapy. Value Health 2008, 11, 1144-1153. [CrossRef] [PubMed]

40. Joyce, V.R.; Barnett, P.G.; Bayoumi, A.M.; Griffin, S.C.; Kyriakides, T.C.; Yu, W.; Sundaram, V.; Holodniy, M.; Brown, S.T.; Cameron, W.; et al. Health-related quality of life in a randomized trial of antiretroviral therapy for advanced HIV disease. J. Acquir. Immune Defic. Syndr. 2009, 50, 27-36. [CrossRef] [PubMed]

41. Molina, J.M.; Capitant, C.; Spire, B.; Pialoux, G.; Cotte, L.; Charreau, I.; Tremblay, C.; Le Gall, J.M.; Cua, E.; Pasquet, A.; et al. On-Demand Preexposure Prophylaxis in Men at High Risk for HIV-1 Infection. N. Engl. J. Med. 2015, 373, 2237-2246. [CrossRef] [PubMed]

42. Baeten, J.M.; Donnell, D.; Ndase, P.; Mugo, N.R.; Campbell, J.D.; Wangisi, J.; Tappero, J.W.; Bukusi, E.A.; Cohen, C.R.; Katabira, E.; et al. Antiretroviral prophylaxis for HIV prevention in heterosexual men and women. N. Engl. J. Med. 2012, 367, 399-410. [CrossRef] [PubMed]

43. Amico, K.R.; Marcus, J.L.; Mcmahan, V.; Liu, A.; Koester, K.A.; Goicochea, P.; Anderson, P.L.; Glidden, D.; Guanira, J.; Grant, R. Study product adherence measurement in the iPrEx placebo-controlled trial: Concordance with drug detection. J. Acquir. Immune Defic. Syndr. 2014, 66, 530-537. [CrossRef] [PubMed]

44. Hankins, C.A.; Glasser, J.W.; Chen, R.T. Modeling the impact of RV144-like vaccines on HIV transmission. Vaccine 2011, 29, 6069-6071. [CrossRef] [PubMed]

45. Moody, M.A.; Easterhoff, D.; Gurley, T.C.; Whitesides, J.F.; Marshall, D.J.; Foulger, A.; Lloyd, K.E.; Parks, R.; Pollara, J.; Duffy, R.; et al. Induction of antibodies with long variable heavy third complementarity determining regions by repetitive boosting with aidsvax ${ }^{\circledR}$ B/E in RV144 vaccinees. AIDS Res. Hum. Retroviruses 2014, 30, A36.

46. United States Department of Labor Bureau of Labor Statistics. Measuring Price Change for Medical Care in the CPI. Consum Price Index 2017. Available online: https:/ /www.bls.gov/cpi/cpifact4.htm (accessed on 22 April 2017).

47. Bureau of Labor Statistics. Consumer Price Index Detailed Report: Data for October 2016; Bureau of Labor Statistics: Washington, DC, USA, 2016. 
48. Gebo, K.A.; Fleishman, J.A.; Conviser, R.; Hellinger, J.; Hellinger, F.J.; Josephs, J.S.; Keiser, P.; Gaist, P.; Moore, R.D. Contemporary costs of HIV healthcare in the HAART era. AIDS 2010, 24, 2705-2715. [CrossRef] [PubMed]

49. U.S. Department of Veterans Affairs. Department of Veterans Affairs. National Acquisition Center (CCST) n.d. Available online: http://www1.va.gov/nac/ (accessed on 10 October 2016).

50. Seage, G.R. Are US populations appropriate for trials of human immunodeficiency virus vaccine?: The HIVNET vaccine preparedness study. Am. J. Epidemiol. 2001, 153, 619-627. [CrossRef] [PubMed]

51. National Institute of Allergy and Infectious Diseases. NIH-Sponsored HIV Vaccine Trial Launches in South Africa: Early-Stage Trial Aims to Build on RV144 Results. NIH News 2015. Available online: http: //www.niaid.nih.gov/news/newsreleases/2015/Pages/HVTN100.aspx (accessed on 31 July 2015).

52. Molina, J.-M.; Capitant, C.; Spire, B.; Pialoux, G.; Chidiac, C.; Charreau, I.; Delfraissy, J.F. On Demand PrEP With Oral TDF-FTC in MSM: Results of the ANRS Ipergay Trial. In Proceedings of the Conference on Retroviruses Opportunistic Infection, Seattle, WA, USA, 23-26 Febuary 2017.

53. Sirivichayakul, S.; Phanuphak, P.; Hanvanich, M.; Ruxrungtham, K.; Panmoung, W.; Thanyanon, W. Clinical correlation of the immunological markers of HIV infection in individuals from Thailand. AIDS 1992, 6, 393-397. [CrossRef] [PubMed]

54. Gold, M.; Siegel, J.; Russell, L.; Weinstien, M. Cost-Effectiveness in Health and Medicine; Oxford University Press: New York, NY, USA, 1996.

55. Briggs, A.; Claxton, K.; Sculpher, M. Decision Modelling for Health Economic Evaluation, 1st ed.; Oxford University Press: London, UK, 2006.

56. Neumann, P.J.; Cohen, J.T. Measuring the value of prescription drugs. N. Engl. J. Med. 2015. [CrossRef] [PubMed]

57. The Congress of the United States Congressional Budget Office. How Increased Competition from Generic Drugs Has Affected Prices and Returns in the Pharmaceutical Industry; The Congress of the United States Congressional Budget Office: Washington, DC, USA, 1998.

58. Bach, P.B. Indication-specific pricing for cancer drugs. JAMA 2014, 312, 1629-1630. [CrossRef] [PubMed]

59. Bush, S.; Ng, L.; Magnuson, D.; Piontkowsky, D.; Mera Giler, R. Significant uptake of truvada for pre-exposure prophylaxis (PrEP) utilization in the US in Late 2014-1Q2015. In Proceedings of the IAPAC Treatment and Prevention Adherence Conference, Miami, FL, USA, 28-30 June 2015.

60. Schneider, K.; Gray, R.T.; Wilson, D.P. A cost-effectiveness analysis of HIV preexposure prophylaxis for men who have sex with men in Australia. Clin. Infect. Dis. 2014, 58, 1027-1034. [CrossRef] [PubMed]

61. Ouellet, E.; Durand, M.; Guertin, J.R.; LeLorier, J.; Tremblay, C.L. Cost effectiveness of “on demand" HIV pre-exposure prophylaxis for non-injection drug-using men who have sex with men in Canada. Can. J. Infect. Dis. Med. Microbiol. 2015, 26, 23-29. [CrossRef] [PubMed]

62. Hall, H.I.; An, Q.; Tang, T.; Song, R.; Chen, M.; Green, T.; Kang, J. Prevalence of diagnosed and undiagnosed HIV infection-United States, 2008-2012. MMWR 2015, 64, 657-662. [PubMed]

63. Centers for Disease Control and Prevention. HIV Surveillance Report, Diagnoses of HIV Infection in the United States and Dependent Areas, 2014; Centers for Disease Control and Prevention: Atlanta, GA, USA, 2014.

64. Walensky, R.P.; Jacobsen, M.M.; Bekker, L.G.; Parker, R.A.; Wood, R.; Resch, S.C.; Horstman, N.K.; Freedberg, K.A.; Paltiel, A.D. Potential clinical and economic value of long-acting preexposure prophylaxis for South African women at high-risk for HIV infection. J. Infect. Dis. 2015. [CrossRef] [PubMed]

65. Schackman, B.R.; Fleishman, J.A.; Su, A.E.; Berkowitz, B.K.; Moore, R.D.; Walensky, R.P.; Becker, J.E.; Voss, C.; Paltiel, A.D.; Weinstein, M.C.; et al. The lifetime medical cost savings from preventing HIV in the United States. Med. Care 2015, 53, 293-301. [CrossRef] [PubMed]

66. Farnham, P.G.; Gopalappa, C.; Sansom, S.L.; Hutchinson, A.B.; Brooks, J.T.; Weidle, P.J.; Marconi, V.C.; Rimland, D. Updates of lifetime costs of care and quality-of-life estimates for HIV-infected persons in the United States. J. Acquir. Immune Defic. Syndr. 2013, 64, 183-189. [CrossRef] [PubMed]

(C) 2017 by the authors. Licensee MDPI, Basel, Switzerland. This article is an open access article distributed under the terms and conditions of the Creative Commons Attribution (CC BY) license (http:/ / creativecommons.org/licenses/by/4.0/). 